Pacific Journal of Mathematic 


\title{
THE SCHOLZ-BRAUER PROBLEM ON ADDITION CHAINS
}

\author{
EDWARD G. THURBER
}

\begin{abstract}
An addition chain for a positive integer $n$ is a set $1=$ $a_{0}<a_{1}<\cdots<a_{r}=n$ of integers such that every element $a_{i}$ is the sum $a_{j}+a_{k}$ of two preceding members (not necessarily distinct) of the set. The smallest length $r$ for which an addition chain for $n$ exists is denoted by $l(n)$. Let $\lambda(n)=$ $\left[\log _{2} n\right]$, and let $\nu(n)$ denote the number of ones in the binary representation of $n$. The purpose of this paper is to show how to establish the result that if $\nu(n) \geqq 9$ then $l(n) \geqq \lambda(n)+$ 4. This is the $m=3$ case of the conjecture that if $\nu(n) \geqq 2^{m}+$ 1 then $l(n) \geqq \lambda(n)+m+1$ for which cases $m=0,1,2$ have previously been estabished. The fact that the conjecture is true for $m=3$ leads to the theorem that $n=2^{m}(23)+7$ for $m \geqq 5$ is an infinite class of integers for which $l(2 n)=l(n)$. The paper concludes with this result.
\end{abstract}

An addition chain for a positive integer $n$ is a set $1=a_{0}<a_{1}<$ $a_{2}<\cdots<a_{r}=n$ of integers such that every element $a_{i}$ is the sum $a_{j}+a_{k}$ of two preceding members (not necessarily distinct) of the set. The smallest length $r$ for which an addition chain for $n$ exists is denoted by $l(n)$. Let $\lambda(n)=\left[\log _{2} n\right]$, and let $\nu(n)$ denote the number of ones in the binary representation of $n$. Step $i$ of an addition chain is $a_{i}=a_{j}+a_{k}$ for some $k \leqq j<i$. Since $a_{i} \leqq 2 a_{j} \leqq 2 a_{i-1}$, either $\lambda\left(a_{i}\right)=$ $\lambda\left(a_{i-1}\right)$ or $\lambda\left(a_{i}\right)=\lambda\left(a_{i-1}\right)+1$. Step $i$ is called a small step in the former case and a big step in the latter case. Since $a_{i} \leqq 2 a_{i-1}$, a member of the chain must occur in each of the half-open intervals $\left[2^{k}, 2^{k+1}\right.$ ) for $0 \leqq k \leqq \lambda(n)$. Every time a step takes the chain from one interval to the next it is a big step; otherwise, it is a small step. There are $\lambda(n)$ big steps in the chain, and the remaining steps are small steps. If $N\left(a_{i}\right)$ represents the number of small steps in the chain to $a_{i}$, then the length $r$ of the chain may be expressed as $r=\lambda(n)+N(n)$.

A conjecture which is equivalent to one made by K. B. Stolarsky [10] states that if $\nu(n) \geqq 2^{m}+1$, then $l(n) \geqq \lambda(n)+m+1$. That is to say if $\nu(n) \geqq 2^{m}+1$, then there are at least $m+1$ small steps in any chain for $n$. The conjecture is true for $m=0,1,2$. These results may be found in [8] with the case $m=2$ being part of D. E. Knuth's Theorem C. The primary purpose of this paper is to show how to establish the conjecture for $m=3$ and to show this case leads to the result that there is an infinite class of integers for which $l(2 n)=l(n)$.

If $a_{j}$ and $a_{k}$ are two integers written in binary notation and placed one on top of the other in order to add or subtract, the resultant 
figure is called a configuration and is designated by $a_{j} / a_{k}$. The configuration is divided up into slots numbered from left to right. If $a_{j}=101100111$ and $a_{k}=10101110$, then $a_{j} / a_{k}$ is as follows:

$$
\begin{aligned}
& \begin{array}{lllllllll}
1 & 2 & 3 & 4 & 5 & 6 & 7 & 8 & 9
\end{array} \\
& a_{j}=10101100011 \\
& a_{k}=10101110 \text {. }
\end{aligned}
$$

The slot numbers are written above. Slot 4 is called a $1 / 1$ slot, slot 9 is a $1 / 0$ slot etc. Two lemmas which involve integers written in their binary notation are the following:

LEMMA 1. If $a_{i}=a_{j}+a_{k}$ and if $c$ represents the number of carries in $a_{j}+a_{k}$, then $\nu\left(a_{i}\right)=\nu\left(a_{j}\right)+\nu\left(a_{k}\right)-c$.

LEMMA 2. If $a_{t}=a_{j}-a_{k}$ and there are $s 1 / 1$ slots in $a_{j} / a_{k}$ and $a$ one appears in $a_{t} p$ times under either a $1 / 1$ slot or a 0/0 slot, then $\nu\left(a_{t}\right)=\nu\left(a_{j}\right)-s+p$.

Two further lemmas will now be given which involve numbers in an addition chain.

LEMMA 3. If $a_{j}$ and $a_{k}$ are two members of an addition chain and if $\lambda\left(a_{j}\right)=\lambda\left(a_{k}\right)+m(m \geqq 0)$ and $2^{m} a_{k}<a_{j}$, then $N\left(a_{j}\right) \geqq N\left(a_{k}\right)+1$.

Proof. Since $\lambda\left(a_{j}\right)=\lambda\left(a_{k}\right)+m$, there are precisely $m$ big steps from $a_{k}$ to $a_{j}$ in the chain, but $2^{m} a_{k}<a_{j}$ implies that there are at least $m+1$ steps in the chain from $a_{k}$ to $a_{j}$; hence, at least one of them is a small step.

LEMMA 4. If $a_{j}$ and $a_{k}$ are two members of an addition chain and if $\lambda\left(a_{j}\right)=\lambda\left(a_{k}\right)+m(m \geqq 2)$ and $a_{j}>2^{m-1} a_{k}+2^{m-2} a_{k}$, then $N\left(a_{j}\right) \geqq$ $N\left(a_{k}\right)+1$ unless $a_{j}=2^{m-1} a_{k+1}$.

Proof. Suppose that there are no small steps from $a_{k}$ to $a_{j}$. Assume that there is at least one $t$ such that $2 \leqq t \leqq m$ and $a_{k+t} \neq$ $2 a_{k+t-1}$. Then $a_{k+t} \leqq a_{k+t-1}+a_{k+t-2} \leqq 2^{t-1} a_{k}+2^{t-2} a_{k}$ which implies that $a_{k+m}=a_{k+t+(m-t)} \leqq 2^{m-t} a_{k+t} \leqq 2^{m-t}\left(2^{t-1} a_{k}+2^{t-2} a_{k}\right)=2^{m-1} a_{k}+2^{m-2} a_{k}<a_{j}$. Thus, $a_{k+m}<a_{j}$ which implies that there is at least one small step from $a_{k}$ to $a_{j}$ which is a contradiction. Therefore, if there are no small steps from $a_{k}$ to $a_{j}$, then $a_{k+t}=2 a_{k+t-1}$ for $2 \leqq t \leqq m$ which implies that $a_{j}=2^{m-1} a_{k+1}$. It follows that if $a_{j} \neq 2^{m-1} a_{k+1}$, then $N\left(a_{j}\right) \geqq$ $N\left(a_{k}\right)+1$.

Knuth's Theorem C [8] along with the four previous lemmas will be much used in the work that follows. The statement of Theorem 
C follows with the integers being expressed in binary form.

THEOREM C. If $\nu(n) \geqq 4$, then $l(n) \geqq \lambda(n)+3$ except when $\nu(n)=$ 4 and $n$ has one of the four following forms: (A) $n=1 \cdots d \cdots 1 \cdots$ $1 \cdots d \cdots 1 \cdots$ where $d$ indicates the number of zeros between the first and second one and between the third and fourth one. (B) $n=1 \cdots d \cdots 1 \cdots 1 \cdots e \cdot \cdots 1 \cdots$ where $d$ and $e$ again indicate zeros and $e=d-1$. (C) $n=1001 \cdots 11 \cdots$. (D) $n=10000111 \ldots$. In these four cases $l(n)=\lambda(n)+2$.

The $m=3$ case of the conjecture will now be stated as a theorem, and the method of proof will be described.

THEOREM 1. If $\nu(n) \geqq 9$, then $l(n) \geqq \lambda(n)+4$.

Proof. Let $1=a_{0}<a_{1}<\cdots<a_{r}=n$ be an addition chain for an integer $n$ for which $\nu(n) \geqq 9$. Let $a_{i}$ denote the first member of the chain for which $\nu\left(a_{i}\right) \geqq 9$. Then $a_{i}=a_{j}+a_{k}$ where $k<j$ since if $k=j$, then $a_{i}=2 a_{j}$ which would mean that $\nu\left(a_{i}\right)=\nu\left(a_{j}\right)$. Thus, $a_{j}$ and $a_{k}$ are distinct members of the chain, and since $\nu\left(a_{j}\right) \leqq 8$ and $\nu\left(a_{k}\right) \leqq 8$, it follows from Lemma 1 that $9 \leqq \nu\left(a_{i}\right) \leqq 16$. Each of the eight cases for $\nu\left(a_{i}\right)$ must be considered, and for each of these cases the possibilities for $\nu\left(a_{j}\right)$ and $\nu\left(a_{k}\right)$ must be considered. For convenience the various cases will be listed as ordered triples $\left(\nu\left(a_{i}\right), \nu\left(a_{j}\right), \nu\left(a_{k}\right)\right)$. There are 120 cases altogether. The case $(9,5,4)$ will be considered first.

By Lemma $1 c=0$ for $(9,5,4)$, and the only possibility for $a_{j} / a_{k}$ is:

$$
\begin{aligned}
a_{j} & =1 \cdots \cdots \\
+a_{k} & =\cdots 1 \cdots \\
a_{i} & =1 \cdots \cdots .
\end{aligned}
$$

As can be seen $\lambda\left(a_{i}\right)=\lambda\left(a_{j}\right)$ and, thus, there is at least one small step from $a_{j}$ to $a_{i}$. Case $m=2$ of the conjecture implies that $N\left(a_{j}\right) \geqq$ 3 since $\nu\left(a_{j}\right)=5$. Thus, $N(n) \geqq N\left(a_{i}\right) \geqq N\left(a_{j}\right)+1 \geqq 4$.

Case $(9,4,5)$ is virtually the same as $(9,5,4)$ except that it is $N\left(a_{k}\right)$ which is greater than or equal to 3 . Since $N\left(a_{j}\right) \geqq N\left(a_{k}\right)$, it follows as before that $N(n) \geqq 4$.

The 34 additional cases for which $c=0$ are handled in the same manner as these cases.

For $c=1$ there are 28 cases for $\left(\nu\left(a_{i}\right), \nu\left(a_{j}\right), \nu\left(a_{k}\right)\right)$. Since $a_{i} \leqq 2 a_{j}$, either $\lambda\left(a_{i}\right)=\lambda\left(a_{j}\right)$ or $\lambda\left(a_{i}\right)=\lambda\left(a_{j}\right)+1$. If $\lambda\left(a_{i}\right)=\lambda\left(a_{j}\right)$, then as in the cases where $c=0$ it may be concluded that $N(n) \geqq 4$. If $\lambda\left(a_{i}\right)=$ $\lambda\left(a_{j}\right)+1$, then with $c=1$ the only possibility for $a_{j} / a_{k}$ is: 


$$
\begin{aligned}
a_{j} & =1 \cdots \\
+a_{k} & =1 \cdots \\
a_{i} & =10 \cdots .
\end{aligned}
$$

As previously noted $a_{j}$ and $a_{k}$ are distinct members of the chain, and since $\lambda\left(a_{j}\right)=\lambda\left(a_{k}\right)$ it follows that $N\left(a_{j}\right) \geqq N\left(a_{k}\right)+1$. For those cases where $\nu\left(a_{k}\right) \geqq 5, N(n) \geqq N\left(a_{j}\right) \geqq N\left(a_{k}\right)+1 \geqq 4$. When $\nu\left(a_{k}\right) \leqq 4$, some further work is necessary.

The cases where $3 \leqq \nu\left(a_{k}\right) \leqq 4$ shall first be considered. By Lemma $1 \nu\left(a_{j}\right) \geqq 6$ since $c=1 . \quad a_{j} \neq 2 a_{k}$ since $\nu\left(a_{j}\right) \neq \nu\left(a_{k}\right)$, and it follows that either $a_{j}=a_{m}+a_{s}$ where $s \leqq m$ and $a_{m} \neq a_{k}$ or $a_{j}=a_{k}+a_{t}$ where $t<k$. Suppose $a_{j}=a_{m}+a_{s}$ where $a_{m} \neq a_{k}$. Since $a_{j} \leqq 2 a_{m}$, the possibilities on the number line are:

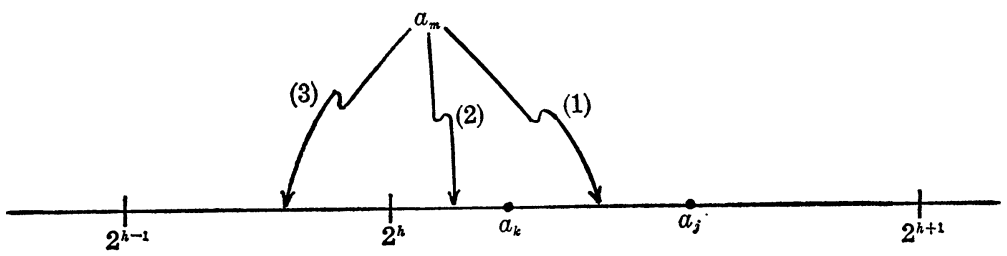

FIGURE 1

In case $(1) N\left(a_{j}\right) \geqq N\left(a_{k}\right)+2 \geqq 4$ since $\nu\left(a_{k}\right) \geqq 3$. In case (2) $N\left(a_{m}\right) \geqq$ 2 for if $N\left(a_{m}\right) \leqq 1$, then $1=a_{0}<a_{1}<\cdots<a_{m}<a_{j}$ is an addition chain for $a_{j}$ with less than three small steps contradicting the fact that $\nu\left(a_{j}\right) \geqq 5$ implies $N\left(a_{j}\right) \geqq 3$. Thus, $N\left(a_{j}\right) \geqq N\left(a_{m}\right)+2 \geqq 4$. In case (3) similar reasoning shows that $N\left(a_{m}\right) \geqq 3$, and, consequently, $N\left(a_{j}\right) \geqq N\left(a_{m}\right)+1 \geqq 4$. In all three cases $N(n) \geqq N\left(a_{j}\right) \geqq 4$.

Suppose $a_{j}=a_{k}+a_{t}$ where $t<k<j$. Then $a_{t}=a_{j}-a_{k}$. Since $c=1$ there is only one $1 / 1$ slot in $a_{j} / a_{k}$. When $a_{j} / a_{k}$ is considered from a subtraction point of view, it follows from Lemma 2 that $\nu\left(a_{t}\right) \geqq 5$ which means that $N\left(a_{t}\right) \geqq 3$. Thus, $N(n) \geqq N\left(a_{j}\right) \geqq N\left(a_{k}\right)+1 \geqq N\left(a_{t}\right)+$ $1 \geqq 4$.

All cases for $c=1$ have been dispensed with except $(9,8,2)$. In this case $\nu\left(a_{k}\right)=2$ implies $N\left(a_{k}\right) \geqq 1$. If $N\left(a_{k}\right)=1$, then it may be concluded that all members of the chain preceding $a_{k}$ have two or less ones in their binary representation. Thus, $\nu\left(a_{k+1}\right) \leqq 4$ and $\nu\left(a_{k+2)}\right) \leqq$ 6. Since $\lambda\left(a_{j}\right)=\lambda\left(a_{k}\right)$, this means that $N(n) \geqq N\left(a_{j}\right) \geqq N\left(a_{k}\right)+3 \geqq 4$. If $N\left(a_{k}\right) \geqq 2$, then $N(n) \geqq 4$ in the same manner as when $3 \leqq \nu\left(a_{k}\right) \leqq 4$.

For $c=2$ the cases where $\nu\left(a_{j}\right) \geqq 5, \nu\left(a_{k}\right) \geqq 5$, and $\nu\left(a_{j}\right) \neq \nu\left(a_{k}\right)$ are handled rather easily. As with the $c=1$ cases it may be supposed that $\lambda\left(a_{i}\right)=\lambda\left(a_{j}\right)+1$. If $\lambda\left(a_{j}\right)=\lambda\left(a_{k}\right)$, then $N(n) \geqq N\left(a_{j}\right) \geqq N\left(a_{k}\right)+$ $1 \geqq 4$. Thus, it may be supposed that $\lambda\left(a_{j}\right)>\lambda\left(a_{k}\right)$, and the only possibility for $a_{j} / a_{k}$ with $c=2$ is: 


$$
\begin{aligned}
a_{j} & =11 \cdots \\
+a_{k} & =1 \cdots \\
a_{i} & =100 \cdots .
\end{aligned}
$$

If $a_{j}=a_{m}+a_{s}$ where $s \leqq m<j$ and $a_{m} \neq a_{k}$, then there are three possibilities on the number line:

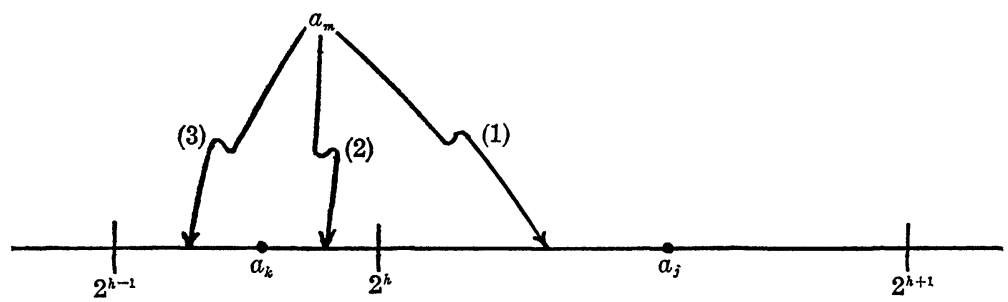

Figure 2

In cases (1) and (2) $N(n) \geqq N\left(a_{j}\right) \geqq N\left(a_{k}\right)+1 \geqq 4$ since $\nu\left(a_{k}\right) \geqq 5$. In case (3) $N\left(a_{m}\right) \geqq 3$ or else $1=a_{0}<a_{1}<\cdots<a_{m}<a_{j}$ is a chain for $a_{j}$ with less than three small steps which contradicts $\nu\left(a_{j}\right) \geqq 5$. Thus, $N(n) \geqq N\left(a_{j}\right) \geqq N\left(a_{m}\right)+1 \geqq 4$. If $a_{j}=a_{k}+a_{t}$, then $a_{t}=a_{j}-a_{k}$. Since $c=2$, there can be no more $1 / 1$ slots in $a_{j} / a_{k}$, and since $\nu\left(a_{j}\right) \neq$ $\nu\left(a_{k}\right), a_{j} \neq 2 a_{k}$ which means that $a_{k}$ and $a_{t}$ are distinct members of the chain. $a_{j} / a_{k}$ then looks as follows:

$$
\begin{aligned}
a_{j} & =11 \cdots \\
-a_{k} & =1 \cdots \\
a_{t} & =1 \cdots .
\end{aligned}
$$

By Lemma $2 \nu\left(a_{t}\right) \geqq 5$ since $\nu\left(a_{j}\right) \geqq 5$. Since $\lambda\left(a_{k}\right)=\lambda\left(a_{t}\right), N(n) \geqq$ $N\left(a_{k}\right) \geqq N\left(a_{t}\right)+1 \geqq 4$.

There are 12 cases for which $c=2, \nu\left(a_{j}\right) \geqq 5, \nu\left(a_{k}\right) \geqq 5$, and $\nu\left(a_{j}\right) \neq$ $\nu\left(a_{k}\right)$. Thus, 76 of the 120 cases for $\left(\nu\left(a_{i}\right), \nu\left(a_{j}\right), \nu\left(a_{k}\right)\right)$ have been dispensed with so far. In $(10,6,6),(12,7,7)$, and $(14,8,8) \nu\left(a_{j}\right)=\nu\left(a_{k}\right)$, and it is possible that $a_{j}=2 a_{k}$. This means that $a_{k}=a_{t}$; hence, $a_{k}$ and $a_{t}$ are not distinct members of the chain. Thus, the statement that $N\left(a_{k}\right) \geqq N\left(a_{t}\right)+1$ cannot be made as with the other cases where $c=2$ and $\nu\left(a_{j}\right) \geqq 5$ and $\nu\left(a_{k}\right) \geqq 5$. Some additional concepts need to be discussed at this point which make it possible to dispense with cases such as these.

Let $l_{8}(n)$ denote the minimal length of an addition chain for an integer $n$ all of whose members have eight or less ones in their binary representation. A list of propositions concerning $l_{8}(n)$ will now be given. The proof of one of these propositions will then be given. The proofs of the others are similar. 
Proposition 1. If $\nu(n)=7$ and $n=111 \cdots$, then $l_{8}(n) \geqq \lambda(n)+4$.

Proposition 2. If $\nu(n)=8$ and $n=111 \cdots$, then $l_{8}(n) \geqq \lambda(n)+$ 4 unless $n=1111 \cdots 1111 \cdots$.

Proposition 3. If $\nu(n)=7$ and $n=110 \cdots$, then $l_{8}(n) \geqq \lambda(n)+4$ unless $n=11001 \cdots 1111 \cdots$.

Proposition 4. If $\nu(n)=8$ and $n=110 \cdots$, then $l_{8}(n) \geqq \lambda(n)+$ 4 unless

$$
n=11 \cdots d \cdots 11 \cdots 11 \cdots e \cdot \cdots 11 \cdots \text { where } e=d \text { or } e=d-1 .
$$

(Note: The $d$ and $e$ again stand for $d$ and $e$ zeros respectively between the ones.)

Proposition 5. If $\nu(n)=6$ and $n=111 \cdots$, then $l_{8}(n) \geqq \lambda(n)+$ 4 unless $n=111 \cdots 111 \cdots, 111001011 \cdots, 1111 \cdots 1001 \cdots, 1111 \cdots 101 \cdots$, or $1111 \cdots 11 \cdots$.

Proposition 6. If $\nu(n)=7$ and $n=10111 \cdots 01 \cdots 01 \cdots 01 \cdots$, then $l_{8}(n) \geqq \lambda(n)+4$.

Proposition 7. If $\nu(n)=8$ and $n=1011111 \cdots 01 \cdots 01 \cdots$, then $l_{8}(n) \geqq \lambda(n)+4$.

Proposition 8. If $\nu(n)=8$ and

$$
\begin{array}{r}
n=10111 \cdots 01 \cdots 01 \cdots 0011 \cdots, \\
01 \cdots 0011 \cdots 01 \cdots, \\
0011 \cdots 01 \cdots 01 \cdots,
\end{array}
$$

then $l_{8}(n) \geqq \lambda(n)+4$.

Proposition 9. If $\nu(n)=8$ and

$$
\begin{array}{r}
n=1011 \cdots 01 \cdots 01 \cdots 00111 \cdots, \\
01 \cdots 00111 \cdots 01 \cdots, \\
00111 \cdots 01 \cdots 01 \cdots,
\end{array}
$$

then $l_{8}(n) \geqq \lambda(n)+4$.

Proposition 10. If $\nu(n)=8$ and $n=1010111 \cdots 01 \cdots 01 \cdots 01 \cdots$, then $l_{8}(n) \geqq \lambda(n)+4$.

Proposition 11. If $\nu(n)=8$ and $n=1011011 \cdots 01 \cdots 01 \cdots 01$, 
then $l_{8}(n) \geqq \lambda(n)+4$.

Proposition 12. If $\nu(n)=6$ and $n=11 \cdots 01 \cdots 01 \cdots 01 \cdots 01 \cdots$, then $l_{8}(n) \geqq \lambda(n)+4$.

Proposition 13. If $\nu(n)=7$ and $n=1011 \cdots 01 \cdots 01 \cdots 01 \cdots 01 \cdots$, then $l_{8}(n) \geqq \lambda(n)+4$.

Proposition 14. If $\nu(n)=8$ and $n=101111 \ldots 01 \cdots 01 \cdots 01 \cdots$, then $l_{8}(n) \geqq \lambda(n)+4$.

Proposition 15. If $\nu(n)=8$ and $n=101011 \cdots 01 \cdots 01 \cdots 01 \cdots 01 \cdots$, then $l_{8}(n) \geqq \lambda(n)+4$.

Proposition 16. If $\nu(n)=8$ and

$$
\begin{array}{r}
n=1011 \cdots 01 \cdots 01 \cdots 01 \cdots 0011 \cdots, \\
01 \cdots 01 \cdots 0011 \cdots 01 \cdots, \\
01 \cdots 0011 \cdots 01 \cdots 01 \cdots, \\
0011 \cdots 01 \cdots 01 \cdots 01 \cdots,
\end{array}
$$

then $l_{8}(n) \geqq \lambda(n)+4$.

Proposition 17. If $\nu(n)=8$ and $n=10111 \cdots 01 \cdots 01 \cdots 01 \cdots$ $01 \cdots$, then $l_{8}(n) \geqq \lambda(n)+4$.

Proposition 18. If $\nu(n)=8$ and $n=1011 \cdots 01 \cdots 01 \cdots 01 \cdots$ $01 \cdots 01 \cdots$, then $l_{8}(n) \geqq \lambda(n)+4$.

Proposition 19. If $\nu(n)=7$ and $n=1011100 \cdots 111$, then $l_{8}(n) \geqq$ $\lambda(n)+4$.

Proof. (Prop. 1) Let $1=a_{0}<a_{1}<\cdots<a_{r}=n$ be an addition chain for $n$ where $\nu(n)=7$ and $n=111 \cdots$. It shall be assumed that all members of the chain have eight or less ones in their binary representation. Let $a_{i}$ denote the first member of the chain for which $\nu\left(a_{i}\right)=7$ and $a_{i}=111 \cdots a_{i}=a_{j}+a_{k}$ for some $k \leqq j<i$. In fact $k<j$ for if $a_{j}=a_{k}$ then $a_{i}=2 a_{j}$ which would mean that $\nu\left(a_{j}\right)=7$ and $a_{j}=111 \cdots$ contradicting the fact that $a_{i}$ was chosen as the first member of the chain having these properties. Thus, $a_{j}$ and $a_{k}$ are distinct members of the chain and $1 \leqq \nu\left(a_{j}\right), \nu\left(a_{k}\right) \leqq 8$. The 49 cases for $\left(\nu\left(a_{j}\right), \nu\left(a_{k}\right)\right)$ must be considered.

$a_{i} \leqq 2 a_{j}$ implies that $\lambda\left(a_{i}\right)=\lambda\left(a_{j}\right)$ or $\lambda\left(a_{i}\right)=\lambda\left(a_{j}\right)+1$. If $\nu\left(a_{k}\right) \geqq$ 5 , it may be assumed that $\lambda\left(a_{i}\right)=\lambda\left(a_{j}\right)+1$; otherwise, $N(n) \geqq N\left(a_{i}\right) \geqq$ $N\left(a_{j}\right)+1 \geqq N\left(a_{k}\right)+1 \geqq 4$. However, if $\lambda\left(a_{i}\right)=\lambda\left(a_{j}\right)+1$, the only 
way to obtain $a_{i}=111 \ldots$ is if $a_{j} / a_{k}$ is as follows:

$$
\begin{aligned}
a_{j} & =\overline{111} \ldots \\
+a_{k} & =11 \ldots . \\
a_{i} & =111 \ldots .
\end{aligned}
$$

The arrows indicate that at least three carries are needed with this configuration. As can be seen $\lambda\left(a_{j}\right)=\lambda\left(a_{k}\right)$, and it follows that $N(n) \geqq$ $N\left(a_{j}\right) \geqq N\left(a_{k}\right)+1 \geqq 4$ for all cases where $\nu\left(a_{k}\right) \geqq 5$. If $\nu\left(a_{k}\right) \leqq 4$ and $\nu\left(a_{j}\right) \geqq 5$, then the configuration still holds, and all cases where $\nu\left(a_{j}\right)=$ 7 may be dispensed with since $a_{j}=111 \ldots$ again contradicts the "firstness" of $a_{i}$. The cases $(8,1),(6,3),(6,2),(6,1),(5,4),(5,3)$, and $(5,2)$ all have less than three carries in $a_{j}+a_{k}$ by Lemma 1 while at least three carries are needed in the configuration. In case $(8,2)$ only two carries are possible while three are needed. In $(8,3)$ it may be assumed as with case $(10,8,3)$ of Theorem 1 that $a_{j}=a_{k}+a_{t}$ (see Figure 1). $a_{t}=a_{j}-a_{k}$, and by Lemma $2 \nu\left(a_{t}\right) \geqq 5$ which implies that $N(n) \geqq N\left(a_{j}\right) \geqq N\left(a_{k}\right)+1 \geqq N\left(a_{t}\right)+1 \geqq 4$. In $(8,4)$ it may be assumed that $a_{k}$ is one of the four special types in Theorem C; otherwise, $N\left(a_{k}\right) \geqq 3$ which implies $N(n) \geqq N\left(a_{j}\right) \geqq N\left(a_{k}\right)+1 \geqq 4$. Since $a_{k}=11 \cdots$, this means that $a_{k}=11 \cdots 11 \cdots$. As in $(8,3)$ it may be assumed that $a_{j}=a_{k}+a_{t}$, and as with $(8,3) \nu\left(a_{t}\right) \geqq 5$ unless there are four $1 / 1$ slots in $a_{j} / a_{k}$. By Lemma $1 c=5$ in $a_{j}+a_{k}$, and the only way to meet all of these requirements is if $a_{j} / a_{k}$ is as follows:

$$
\begin{aligned}
& a_{j}=11111 \cdots 1 \cdots 1 \cdots 1 \cdots \text { implies } a_{j}=11111 \cdots 1 \cdots 1 \cdots 1 \cdots \\
& +a_{k}=11011 \cdots 0 \cdots 0 \cdots 0 \cdots \quad-a_{k}=11011 \cdots 0 \cdots 0 \cdots 0 \cdots \\
& a_{i}=111010 \cdots 1 \cdots 1 \cdots 1 \cdots \quad a_{t}=100 \cdots 1 \cdots 1 \cdots 1 \cdots .
\end{aligned}
$$

$\lambda\left(a_{k}\right)=\lambda\left(a_{t}\right)+2$ while $2^{2} a_{t}<a_{k}$, and so by Lemma $3 N\left(a_{k}\right) \geqq N\left(a_{t}\right)+$ $1 \geqq 3$. Thus, $N(n) \geqq N\left(a_{j}\right) \geqq N\left(a_{k}\right)+1 \geqq 4$. In $(6,4) c=3$ by Lemma 1. Therefore, $a_{j} / a_{k}$ must be:

$$
\begin{aligned}
a_{j} & =11 \overline{1} \cdots 1 \cdots 0 \cdots \\
+a_{k} & =111 \cdots 0 \cdots 1 \cdots \\
a_{i} & =1110 \cdots 1 \cdots 1 \cdots
\end{aligned}
$$

By Theorem C $N\left(a_{k}\right) \geqq 3$; hence, $N(n) \geqq N\left(a_{j}\right) \geqq N\left(a_{k}\right)+1 \geqq 4$.

The only remaining cases to be considered are $(4,4),(4,3)$, and $(3,4)$. $\lambda\left(a_{i}\right)=\lambda\left(a_{j}\right)+1$ is not possible since at least three carries are needed while these cases by Lemma 1 have less than two. When either $\nu\left(a_{j}\right)=4$ or $\nu\left(a_{k}\right)=4$, it may be assumed that $a_{j}$ and $a_{k}$ are what shall be called "special fours" meaning that they are one of the types in Theorem C. Otherwise, $N(n) \geqq N\left(a_{i}\right) \geqq N\left(a_{j}\right)+1 \geqq 4$ since it may be assumed that $\lambda\left(a_{i}\right)=\lambda\left(a_{j}\right)$. In $(4,4)$ the possible 
configurations $a_{j} / a_{k}$ for obtaining $a_{i}=111 \ldots$ with $c=1$ are:

(1)

$$
\begin{aligned}
a_{j} & =1001 \cdots \\
+a_{k} & =101 \cdots \\
a_{i} & =1110 \cdots \\
a_{j} & =100 \cdots 01 \cdots \\
+a_{k} & =11 \cdots 01 \cdots \\
a_{i} & =111 \cdots 10 \cdots
\end{aligned}
$$

$$
\text { (2) } \begin{aligned}
a_{j} & =101 \cdots 01 \cdots \\
+a_{k} & =10 \cdots 01 \cdots \\
a_{i} & =111 \cdots 10 \cdots \\
a_{j} & =11 \cdots \\
+a_{k} & =00 \cdots \\
a_{i} & =111 \cdots .
\end{aligned}
$$

In (1), (2), and (3) either $a_{j}=a_{m}+a_{s}$ where $a_{m} \neq a_{k}$ or $a_{j}=a_{k}+a_{t}$. If $a_{j}=a_{m}+a_{s}$, then $N\left(a_{j}\right) \geqq 3$ by reasoning similar to that used in $(9,6,5)$ of Theorem 1 (see Figure 2). Thus, $N(n) \geqq N\left(a_{i}\right) \geqq N\left(a_{j}\right)+$ $1 \geqq 4$. It shall be assumed then that $a_{j}=a_{k}+a_{t}$. In (1) there are two possibilities for $a_{t}=a_{j}-a_{k}$ :

$$
\text { (a) } \begin{array}{rlrl}
a_{j} & =1001 \cdots & \text { (b) } \quad a_{j}=1001 \ldots \\
-a_{k} & =101 \cdots & -a_{k} & =101 \cdots \\
a_{t} & =100 \cdots & a_{t} & =11 \cdots .
\end{array}
$$

Since $c=1$, there can be no further $1 / 1$ slots in $a_{j} / a_{k}$. Thus, in (a) $\nu\left(a_{t}\right) \geqq 3$ by Lemma 2 , and since $\lambda\left(a_{k}\right)=\lambda\left(a_{t}\right)$ and $a_{t} \neq a_{k}$, this means $N(n) \geqq N\left(a_{i}\right) \geqq N\left(a_{j}\right)+1 \geqq N\left(a_{k}\right)+1 \geqq N\left(a_{t}\right)+2 \geqq 4$. In (b) $\nu\left(a_{t}\right) \geqq 5$ by Lemma 2 , and, so, $N(n) \geqq N\left(a_{i}\right) \geqq N\left(a_{j}\right)+1 \geqq N\left(a_{t}\right)+$ $1 \geqq 4$. (2) may be dispensed with in the same manner as (1) part (a) while in (3) since $a_{k}$ is a "special four" $a_{j} / a_{k}$ becomes:

$$
\begin{aligned}
a_{j} & =100 \cdots 010 \cdots \\
-a_{k} & =11 \cdots 011 \cdots \\
a_{t} & =\cdots \cdots 111 \cdots .
\end{aligned}
$$

By Lemma $2 \nu\left(a_{t}\right) \geqq 5$; hence, $N(n) \geqq 4$ as in (1) part (b).

In (4) it may be assumed that the first two digits in $a_{k}$ are ones; otherwise, $\lambda\left(a_{j}\right)=\lambda\left(a_{k}\right)+m$ for some positive integer $m$ while $2^{m} a_{k}<$ $a_{j}$. By Lemma 3 this would mean $N\left(a_{j}\right) \geqq N\left(a_{k}\right)+1 \geqq 3$, and, hence, $N(n) \geqq 4$. Since $a_{j}$ and $a_{k}$ both start with two ones and are "special fours", they must both have the form $11 \cdots 11 \cdots$, but in this event it is not possible to have $c=1$ in $a_{j}+a_{k}$.

In $(4,3)$ and $(3,4) c=0$ which means that there are no $1 / 1$ slots in $a_{j} / a_{k}$. The possibilities for $a_{j} / a_{k}$ are the following:
(1) $a_{j}=101 \ldots$
(2) $a_{j}=100 \cdots$
(3) $a_{j}=110 \cdots$
(4) $a_{j}=111 \cdots$
$+a_{k}=10 \ldots$

$$
+a_{k}=11 \ldots
$$$$
+a_{k}=1 \cdots
$$$$
+a_{k}=000 \cdots
$$$$
a_{i}=111 \ldots
$$$$
a_{i}=111 \ldots
$$$$
a_{i}=111 \ldots
$$$$
a_{i}=111 \cdots \text {. }
$$

In (1) $N(n) \geqq 4$ for both $(4,3)$ and $(3,4)$ by the same reasoning used 
in $(4,4)$ with configuration (1) part (a). The remaining configurations will now be discussed for $(4,3)$.

In (2) $a_{t}=a_{j}-a_{k}$ and by Lemma $2 \nu\left(a_{t}\right) \geqq 4$. Thus, $N\left(a_{t}\right) \geqq 3$ which implies $N(n) \geqq 4$ unless $a_{t}$ is a "special four". Since $a_{k}=11 \cdots$, it may be assumed that $a_{t}$ also starts with two ones by the same reasoning that was used for $a_{k}$ in $(4,4)$ configuration (4). Thus, $a_{t}=$ $11 \cdots 11 \cdots$. Since there can be no ones under a $0 / 0$ slot in $a_{j} / a_{k}$ (otherwise $\nu\left(a_{t}\right) \geqq 5$ ), there are only two possibilities for $a_{j} / a_{k}$ :

$$
\text { (a) } \begin{aligned}
a_{j} & =1001 \cdots 101 \cdots & \text { (b) } a_{j} & =1000111 \cdots \\
-a_{k} & =110 \cdots 010 \cdots & -a_{k} & =111000 \ldots \\
a_{t} & =11 \cdots 011 \cdots & a_{t} & =1111 \cdots .
\end{aligned}
$$

In (a) $N\left(a_{k}\right) \geqq 3$ by arguments used before unless $\mathrm{a}_{k}=a_{t}+a_{u}$ for some $u \leqq t<k$. If $a_{k} / a_{t}$ is examined, it may be seen that $\nu\left(a_{u}\right) \geqq 4$, $\lambda\left(a_{t}\right)=\lambda\left(a_{u}\right)$ and $a_{u} \neq a_{t}$. Thus, $N\left(a_{t}\right) \geqq N\left(a_{u}\right)+1 \geqq 3$ which implies $N(n) \geqq 4$. In (b) $a_{j}$ is not a "special four" and, so, $N(n) \geqq N\left(a_{i}\right) \geqq$ $N\left(a_{j}\right)+1 \geqq 4$.

In (3) $a_{j}=11 \cdots 11 \cdots$ since $a_{j}$ is a "special four". As in configuration $(4)$ of $(4,4)$ it may be assumed that $a_{k}$ starts with two ones. $a_{j} / a_{k}$ is then:

$$
\begin{aligned}
a_{j} & =1100 \cdots 11 \cdots \\
+a_{k} & =11 \cdots 00 \cdots \\
a_{i} & =1111 \cdots 11 \cdots .
\end{aligned}
$$

As can be seen $a_{j}>2 a_{k}+a_{k}$, and, so, by Lemma $4 N\left(a_{j}\right) \geqq N\left(a_{k}\right)+$ $1 \geqq 3$ unless $a_{j}=2 a_{k+1}$. Since $\nu\left(a_{k+1}\right)=4$ and $\lambda\left(a_{k+1}\right)=\lambda\left(a_{k}\right)+1$, it follows as before that $N\left(a_{k+1}\right) \geqq 3$ unless $a_{k+1}=a_{k}+a_{t}$ for some $t \leqq$ $k$. From $a_{j} / a_{k}$ and the fact that $a_{j}=2 a_{k+1}$ it may be determined that $a_{k+1} / a_{k}$ is as follows:

$$
\begin{aligned}
a_{k+1} & =1100 \cdots 11 \cdots \\
-a_{k} & =11 \cdots 00 \cdots \\
a_{t} & =1 \cdots \cdots 1 \cdots .
\end{aligned}
$$

By Lemma $2 \nu\left(a_{t}\right) \geqq 3$. Thus, $N(n) \geqq N\left(a_{i}\right) \geqq N\left(a_{j}\right)+1 \geqq N\left(a_{k}\right)+1 \geqq$ $N\left(a_{t}\right)+2 \geqq 4$.

In (4) $a_{j}=1111 \ldots$ since $a_{j}$ is a "special four", and since $\nu\left(a_{k}\right)=$ 3 , it follows that $\lambda\left(a_{j}\right)=\lambda\left(a_{k}\right)+m$ for some positive integer $m$ while $2^{m} a_{k}<a_{j}$. By Lemma $3 N\left(a_{j}\right) \geqq N\left(a_{k}\right)+1 \geqq 3$ which implies $N(n) \geqq$ 4. Configurations (2), (3), and (4) will now be discussed for $(3,4)$.

In (2) it may again be assumed that $a_{j}=a_{k}+a_{t}$, and $a_{k}=$ $11 \cdots 11 \cdots$ since $a_{k}$ is a "special four". By Lemma $2 \nu\left(a_{t}\right) \geqq 3$, and a one can occur in $a_{t}$ at most once under a $0 / 0$ slot in $a_{j} / a_{k}$ or else 
$\nu\left(a_{t}\right) \geqq 5$. The possibilities for $a_{j} / a_{k}$ are:
(a) $a_{j}=10000 \ldots$
(b) $a_{j}=100 \cdots 100 \cdots$
$-a_{k}=1111 \ldots$
$-a_{k}=11 \cdots 011 \cdots$
$a_{t}=1 \cdots$
$a_{t}=1 \cdots 001 \cdots$
(c) $a_{j}=100000 \ldots$
(d) $a_{j}=100 \cdots 1000 \cdots$
$-a_{k}=11011 \ldots$
$-a_{k}=11 \cdots 0011 \ldots$
$a_{t}=101 \ldots$
$a_{t}=1 \cdots 0101 \ldots$.

In (a) and (b) $\nu\left(a_{t}\right)=3$, and no matter where the remaining ones in $a_{t}$ are placed the conditions of Lemma 3 will apply. In (d) $\nu\left(a_{t}\right)=4$, and, so it may be assumed that $a_{t}$ is a "special four" in which case $a_{t}$ must start as $a_{t}=10 \cdots$. Thus, the conditions of Lemma 3 also apply to (c) and (d), and in all four cases $N\left(a_{k}\right) \geqq N\left(a_{t}\right)+1 \geqq 3$ which implies that $N(n) \geqq 4$.

In (3) it may again be assumed as in configuration $(4)$ of $(4,4)$ that the first two digits of $a_{k}$ are ones, and since $a_{k}$ is a "special four", this means that $a_{k}=11 \cdots 11 \cdots$. As in $(4,3)$ configuration (3) it may also be assumed that $a_{j}=2 a_{k+1}$ and that $a_{k+1}=a_{k}+a_{t}$ for some $t \leqq$ $k$. These facts together with $a_{j} / a_{k}$ determine $a_{k+1} / a_{k}$ :

$$
\begin{aligned}
a_{j} & =1100 \cdots 00 \cdots \text { implies } & a_{k+1} & =1100 \cdots 00 \cdots \\
+a_{k} & =11 \cdots 11 \cdots & -a_{k} & =11 \cdots 110 \cdots \\
a_{i} & =1111 \cdots 11 \cdots & a_{t} & =1 \cdots 10 \cdots .
\end{aligned}
$$

No matter where the other one in $a_{k+1}$ is placed, it can be seen that $\nu\left(a_{t}\right) \geqq 3, \lambda\left(a_{k}\right)=\lambda\left(a_{t}\right)$ and $a_{t} \neq a_{k}$. Thus, $N\left(a_{k}\right) \geqq N\left(a_{t}\right)+1 \geqq 3$ which implies $N(\imath) \geqq 4$.

In (4) $a_{k}$ is a "special four", and the conditions of Lemma 3 will apply unless $a_{k}=111 \cdots . \quad \lambda\left(a_{j}\right)=\lambda\left(a_{k}\right)+m$ for some $m \geqq 2$ while $a_{j}>2^{m-1} a_{k}+2^{m-2} a_{k}$, and, so, by Lemma $4 N\left(a_{j}\right) \geqq N\left(a_{k}\right)+1 \geqq 3$ unless $a_{j}=2^{m-1} a_{k+1}$. As before it may be assumed that $a_{k+1}=a_{k}+a_{t}$ for some $t \leqq k$, and these facts together with $a_{j} / a_{k}$ determine $a_{k+1} / a_{k}$ :

$$
\begin{aligned}
a_{j} & =111 \cdots 0000 \cdots \text { implies } & a_{k+1} & =11100 \cdots \\
+a_{k} & =1111 \cdots & -a_{k} & =1111 \ldots \\
a_{i} & =111 \cdots 1111 \cdots & a_{t} & =1101 \cdots
\end{aligned}
$$

$N\left(a_{k}\right) \geqq N\left(a_{t}\right)+1 \geqq 3$; hence, $N(n) \geqq 4$.

In all 49 cases it has been shown that $N(n) \geqq 4$, and, so, it may be concluded that if $\nu\left(a_{i}\right)=7$ and $a_{i}=111 \cdots$, then $l_{8}(n) \geqq \lambda(n)+4$.

In Proposition $2 a_{i}$ denotes the first member of the chain for which $\nu\left(a_{i}\right)=8, a_{i}=111 \ldots$ but $a_{i} \neq 1111 \ldots 1111 \ldots$. The proof is then carried out in the same manner as the proof of Proposition 1. The 
proofs of the remaining propositions are similar, and as each one is proved it may be used in the proof of the next one. Propositions 1 to 5 are extremely helpful in the proofs of the remaining propositions and in that part of the proof of Theorem 1 that remains. We shall now return to the proof of Theorem 1 to demonstrate how the propositions are used. As an example of the remaining cases $(9,7,7)$ will be examined.

To recall $a_{i}$ is the first member of an addition chain for $n$ for which $\nu\left(a_{i}\right) \geqq 9$. $\quad a_{i}=a_{j}+a_{k}$ where $\nu\left(a_{j}\right) \leqq 8$ and $\nu\left(a_{k}\right) \leqq 8$. The propositions concerning $l_{8}(n)$ are applicable to $a_{j}$ and $a_{k}$ and all other members of the chain preceding $a_{i}$. As in $(9,6,5)$ it may be assumed in $(9,7,7)$ that $\lambda\left(a_{i}\right)=\lambda\left(a_{j}\right)+1$ and $\lambda\left(a_{j}\right)>\lambda\left(a_{k}\right)$. Also if $\lambda\left(a_{j}\right)=$ $\lambda\left(a_{k}\right)+m$, it may be assumed that $a_{j} \geqq 2^{m} a_{k}$ or else by Lemma 3 $N\left(a_{j}\right) \geqq N\left(a_{k}\right)+1 \geqq 4$ which implies $N(n) \geqq 4$. In $(9,7,7) c=5$, and the possibilities for $a_{j} / a_{k}$ are now listed. These possibilities are the ways to proceed from left to right to the first $1 / 1$ slot in $a_{j} / a_{k}$ without exceeding five carries and with the previously mentioned restrictions kept in mind.

$$
\begin{aligned}
& \text { (1) } a_{j}=11 \ldots \\
& \text { (2) } a_{j}=101 \ldots \\
& \text { (3) } a_{j}=111 \ldots . \\
& +a_{k}=11 \ldots \\
& a_{i}=10 \ldots \ldots \\
& +a_{k}=11 \cdots \\
& +a_{k}=111 \ldots \\
& a_{i}=100 \ldots \text {. } \\
& \text { (4) } a_{j}=1011 \ldots \\
& \text { (5) } a_{j}=1001 \ldots \\
& +a_{k}=1011 \ldots \\
& +a_{k}=111 \ldots \\
& a_{i}=1000 \ldots . \\
& a_{i}=1000 \ldots \\
& \text { (7) } \\
& a_{j}=1111 \ldots . . \\
& a_{j}=10101 \ldots \\
& +a_{k}=1111 \ldots \\
& a_{i}=1000 . \ldots . \\
& +a_{k}=1011 \ldots \\
& \text { (6) } a_{j}=1101 \ldots \\
& +a_{k}=11 \ldots \\
& a_{i}=1000 \ldots \text {. } \\
& a_{i}=100000 \ldots \\
& a_{j}=10001 \ldots \\
& +a_{k}=1111 \ldots \\
& a_{i}=100000 \ldots \\
& a_{j}=111110000 \ldots \\
& +a_{k}=11111 \ldots \\
& a_{i}=1000001111 \ldots \text {. }
\end{aligned}
$$

In configurations (3), (5), (6), (7), (9), (10), (11), (12), and (13) Propositions 1 and 3 imply that either $N\left(a_{j}\right) \geqq 4$ or $N\left(a_{k}\right) \geqq 4$. In either event this means that $N(n) \geqq N\left(a_{j}\right) \geqq 4$. In (1) $N(n) \geqq 4$ in the same manner unless $a_{j}$ and $a_{k}$ both have the binary form $11001 \cdots 1111 \cdots$, but in this event it is impossible to arrange $a_{j} / a_{k}$ so that $c=5$. In (2) it may be assumed that $a_{k}=11001 \cdots 1111 \cdots$ and that $a_{j}=a_{k}+$ $a_{t}$ for some $t \leqq k$ (see Figure 2). Since $c=5$ there can be at most 
two more $1 / 1$ slots in $a_{j} / a_{k}$. There are two possibilities for $a_{j} / a_{k}$ :
(a) $a_{j}=101 \cdots \cdots \cdot 00 \cdot \cdots$
(b) $a_{j}=101 \cdots \cdots \cdot 00 \cdots$
$\begin{aligned}-a_{k} & =11001 \cdots 1111 \cdots \\ a_{t} & =10 \cdots \cdots \cdot \cdots\end{aligned}$
$\begin{aligned}-a_{k} & =11001 \cdots 1111 \cdots \\ a_{t} & =1 \cdots \cdots 01 \cdots .\end{aligned}$

In (a) it is impossible to have two further $1 / 1$ slots in $a_{j} / a_{k}$ with zeros under them. Thus, $\nu\left(a_{t}\right) \geqq 5$ by Lemma 2 , and since $\lambda\left(a_{k}\right)=$ $\lambda\left(a_{t}\right)$ and $a_{t} \neq a_{k}, N(n) \geqq N\left(a_{k}\right) \geqq N\left(a_{t}\right)+1 \geqq 4$. Configuration (b) can be filled out a little further by realizing that the 1 can occur under the $1 / 1$ slot only if $a_{j} / a_{k}$ is as follows:

$$
\begin{aligned}
a_{j} & =10100 \cdots \cdots 00 \cdots \\
-a_{k} & =11001 \cdots 1111 \cdots \\
a_{t} & =111 \cdots \cdots 01 \cdots .
\end{aligned}
$$

It is impossible to have zeros in $a_{t}$ under any further $1 / 1$ slots in $a_{j} / a_{k}$, and, so, by Lemma $2 \nu\left(a_{t}\right) \geqq 9$ which contradicts the fact that $a_{i}$ is the first member of the chain for which $\nu\left(a_{i}\right) \geqq 9$. In (4) it may again be assumed that $a_{j}=a_{k}+a_{t}$ for some $t \leqq k . \quad c=5$ implies that there is one more $1 / 1$ slot in $a_{j} / a_{k}$; hence, $\nu\left(a_{t}\right) \geqq 5$ by Lemma 2. It is evident that $\lambda\left(a_{k}\right)=\lambda\left(a_{t}\right)$, and if $a_{t} \neq a_{k}, N(n) \geqq N\left(a_{k}\right) \geqq$ $N\left(a_{t}\right)+1 \geqq 4$. It is possible in this case, however, that $a_{t}=a_{k}$ which means $a_{j}=2 a_{k}$. With $c=5$ the configuration would be:

$$
\begin{aligned}
a_{j} & =101110 \cdots 10 \cdots 10 \cdots 10 \cdots \\
+a_{k} & =101110 \cdots 1 \cdots 01 \cdots 01 \cdots \\
a_{i} & =1000101 \cdots 11 \cdots 11 \cdots 11 \cdots .
\end{aligned}
$$

By Proposition $6 N(n) \geqq N\left(a_{j}\right) \geqq 4$. In (8) it is not possible that $a_{j}=$ $2 a_{k}$, and, so, $N(n) \geqq 4$ as in (4) when $a_{t} \neq a_{k}$. This concludes the proof of $(9,7,7)$.

The proof of the remaining cases is similar. Once Theorem 1 is established it follows that the propositions concerning $l_{8}(n)$ are true in general. That is $l(n)$ may be used in the statements of all of the propositions instead of $l_{8}(n)$. The reason for this is that if an integer with more than eight ones in its binary representation does occur in one of the chains then by Theorem 1 there are at least four small steps in the chain up to that integer which means that $N(n) \geqq 4$. In particular Proposition 19 may be restated to say that if $\nu(n)=7$ and $n=1011100 \cdots 111$, then $l(n) \geqq \lambda(n)+4$. This leads to the result that there exists an infinite class of integers for which $l(2 n)=l(n)$. This is the essence of the following theorem.

THeOREM 2. If $n=2^{m}(23)+7$ where $m \geqq 5$, then $l(2 n)=l(n)=m+8$. 
Proof. $n$ has the binary form $n=1011100 \cdots 111$, and by the restatement of Proposition $19 l(n) \geqq \lambda(n)+4$. On the other hand,

$$
1,2,3,4,7,14,21,23,2(23), \cdots, 2^{m}(23), 2^{m}(23)+7=n
$$

is a chain for $n$ with only four small steps. Thus, $l(n)=\lambda(n)+4$.

$2 n=2^{m+1}(23)+14=1011100 \cdots 1110 . \quad \nu(2 n)=7$ implies that $l(2 n) \geqq$ $\lambda(2 n)+3$ while

$$
1,2,4,5,9,14,23,2(23), \cdots, 2^{m+1}(23), 2^{m+1}(23)+14=2 n
$$

is a chain for $2 n$ with only three small steps. Thus, $l(2 n)=\lambda(2 n)+3$. Since $\lambda(2 n)=\lambda(n)+1=m+5$, it follows that $l(2 n)=\lambda(2 n)+3=$ $\lambda(n)+4=l(n)=m+8$.

More details of the proofs of the Propositions and Theorem 1 are available in [12] and in private manuscripts.

\section{REFERENCES}

1. R. E. Bellman, Advanced problem 5125, Amer. Math. Monthly, 70 (1963), 765.

2. A. T. Brauer, On addition chains, Amer. Math. Soc., 45 (1939), 736-739.

3. P. Erdös, Remarks on number theory III on addition chains, Acta Arith. VI (1960), 77-81.

4. A. A. Gioia, M. V. Subbarao, and M. Sugunumma, The Scholz-Brauer problem in addition chains, Duke Math. J., 29 (1962), 481-487.

5. W. Hansen, Zum Scholz-Brauerchen problem, J. Reine Angew. Math., 202 (1959), 129-136.

6. A. M. Il'in, On additive number chains, Problemy Kibernet, 13 (1965), 245-248.

7. H. Kato, On addition chains, Ph. D. Dissertation, University of Southern California, June, 1970.

8. D. E. Knuth, The Art of Computer Programming, 2 Addison-Wesley, Reading, Mass., (1969), 398-422.

9. A. Scholz, Jahresbericht, Deutsche Math.-Verein., 47 (1937), 41.

10. K. B. Stolarsky, A lower bound for the Scholz-Brauer problem, Canad. J. Math., 21 (1969), 675-683.

11. E. G. Straus, Addition chains of vectors, Amer. Math. Monthly, 71 (1964), 806-808.

12. E. G. Thurber, The Scholz-Brauer problem on addition chains, Ph. D. Dissertation, University of Southern California, September, 1971.

13. W. R. Utz, A note on the Scholz-Brauer problem in addition chains, Proc. Amer. Math. Soc., 4 (1953), 462-463.

14. C. T. Whyburn, A note on addition chains, Proc. Amer. Math. Soc., 16 (1965), 1134.

Received January 1, 1972.

Biola College 


\section{PACIFIC JOURNAL OF MATHEMATICS}

\section{EDITORS}

RICHARD ARENS (Managing Editor) University of California

Los Angeles, California 90024

R. A. Beaumon'T

University of Washington Seattle, Washington 98105
J. Dugundj1*

Department of Mathematics University of Southern California Los Angeles, California 90007

D. Gilbarg and J. Milgram Stanford University Stanford, California 94305

\section{ASSOCIATE EDITORS}

E. F. BECKENBACH

B. H. NeUMANN

F. WOLF

K. YOSHIDA

\section{SUPPORTING INSTITUTIONS}

UNIVERSITY OF BRITISH COLUMBIA CALIFORNIA INSTITUTE OF TECHNOLOGY UNIVERSITY OF CALIFORNIA MONTANA STATE UNIVERSITY UNIVERSITY OF NEVADA NEW MEXICO STATE UNIVERSITY OREGON STATE UNIVERSITY UNIVERSITY OF OREGON OSAKA UNIVERSITY

\section{UNIVERSITY OF SOUTHERN CALIFORNIA STANFORD UNIVERSITY UNIVERSITY OF TOKYO UNIVERSITY OF UTAH WASHINGTON STATE UNIVERSITY UNIVERSITY OF WASHINGTON AMERICAN MATHEMATICAL SOCIETY NAVAL WEAPONS CENTER}

* C. R. DePrima California Institute of Technology, Pasadena, CA 91109, will replace J. Dugundji until August 1974. 


\section{Pacific Journal of Mathematics}

\section{Vol. 49, No. $1 \quad$ May, 1973}

A. Bigard, Free lattice-ordered modules ...........................

Richard Bolstein and Warren R. Wogen, Subnormal operators in strictly cyclic

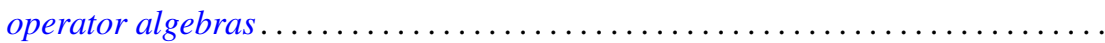

Herbert Busemann and Donald E. Glassco, II, Irreducible sums of simple

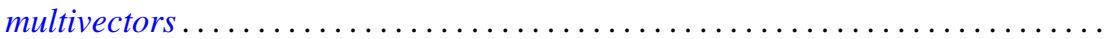

W. Wistar (William) Comfort and Victor Harold Saks, Countably compact groups

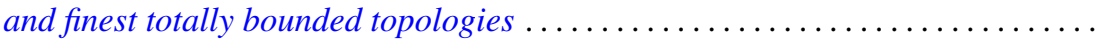

Mary Rodriguez Embry, Maximal invariant subspaces of strictly cyclic operator

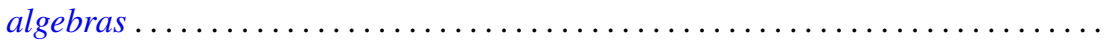

Ralph S. Freese and James Bryant Nation, Congruence lattices of semilattices......

Ervin Fried and George Grätzer, A nonassociative extension of the class of

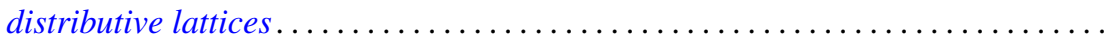

John R. Giles and Donald Otto Koehler, On numerical ranges of elements of locally

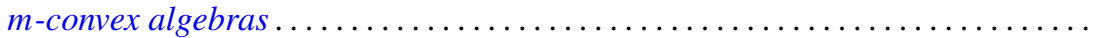

David A. Hill, On dominant and codominant dimension of $\mathrm{QF}-3$ rings ........ John Sollion Hsia and Robert Paul Johnson, Round and Pfister forms over $R(t) \ldots$ I. Martin (Irving) Isaacs, Equally partitioned groups . . . . . . . . . . . . . .

Athanassios G. Kartsatos and Edward Barry Saff, Hyperpolynomial approximation of solutions of nonlinear integro-differential equations.

Shin'ichi Kinoshita, On elementary ideals of $\theta$-curves in the 3-sphere and 2-links in the 4-sphere

Ronald Brian Kirk, Convergence of Baire measures

R. J. Knill, The Seifert and Van Kampen theorem via regular covering spaces ..

Amos A. Kovacs, Homomorphisms of matrix rings into matrix rings ..

Young K. Kwon, HD-minimal but no $H D$-minimal ..........

Makoto Maejima, On the renewal function when some of the mean renewal lifetimes are infinite

Juan José Martínez, Cohomological dimension of discrete modules over profinite groups.

W. K. Nicholson, Semiperfect rings with abelian group of units

Louis Jackson Ratliff, Jr., Three theorems on imbedded prime divisors of principal ideals.

Billy E. Rhoades and Albert Wilansky, Some commutants in $B(c)$ which are almost matrices

John Philip Riley Jr., Cross-sections of decompositions . . .

Keith Duncan Stroyan, A characterization of the Mackey uniformity $m\left(L^{\infty}, L^{1}\right)$ for

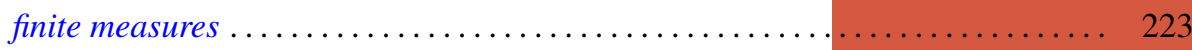

Edward G. Thurber, The Scholz-Brauer problem on addition chains . . . . . . . . . 229

Joze Vrabec, Submanifolds of acyclic 3-manifolds ............

Philip William Walker, Adjoint boundary value problems for compactified singular

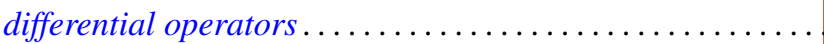

